\title{
Developing Balinese Local Culture Based English E-Media to Support the Implementation of Curriculum 2013 for the First Semester of Grade VII Junior High School
}

\author{
Apsari, Ni Luh Putu Maya \\ Ganesha University of Education \\ maya.apsari@ymail.com
}

\begin{abstract}
This design and development research aimed at designing and developing a culture-based English e-media to support the implementation of curriculum 2013 for the first semester of grade VII of junior high schools in Buleleng sub-district. This research focused on developing e-media that is integrated with Balinese culture. The object of this research was culturebased English e-media that was developed by using Adobe Flash CS6 program. The source of data was taken from the need analysis conducted by Dewi and Batan (2015), related literatures on developing the e-media, and the result of expert judgement. The data were analysed descriptively both qualitatively and quantitatively. This research was designed based on the adaptation of puffers et al.'s model (2007) that consisted of six phases namely: (1) identifying the problem, (2) describing the objective, (3) designing and developing the product, (4) testing the product by using expert judgement, (5) evaluating the testing result, and (6) communicating the testing result. The result of experts' judgement score showed that the total mean score 3.8 which means the e-media had a good quality and it can be used in teaching and learning English for the first semester of grade VII of junior high schools in Buleleng.
\end{abstract}

Keywords: e-media, culture-based, balinese culture

\section{Introduction}

Character education of a nation is the school effort which is done by the teacher and school principal. They do in the lesson and activities outside the lesson in developing character, behavior, moral, and personality of the learners through internalization some virtue that is believed and used by the learners as the basic on the way of view, thinking, behaving, and acting reflecting culture and character. Those are explained in Balitbang National Ministry of Education. It is also stated that character education has function as potential development of the learners become a good behavior for the learners. Character education also has a function in repairing and supporting the national education to be responsible in potential development of better learners. Other significant of that is as filter of cultures of other nation which inappropriate with the nation values and character. Character education is really important in the development of curriculum 2013. It becomes the focus as the goal of curriculum 2013. Curriculum 2013 deserves curriculum which improve the students character to behave well.

Based on the interview, students especially junior high school students are more interested with video rather than picture. Arsyad (2011) states that one function of media is to make the students interested in the material. So, the students would give attention on the material. Animation is can be formed as video that is made based on the material Animation in multimedia is said to be beneficial to learning especially when the learning material demands visual movements (Rias et al. 2011).

Utilizing technology should be the best way of teaching English as Foreign language. Based on the interview with Tina Resdiana, S.Pd, one of the teachers SMP Negeri 2 Singaraja, the use of media in teaching and learning process is very important. It encourages and helps students in understanding the materials. It also creates fun learning environment in the classroom. Thus, technology should be form as teaching and learning media. There are two kinds of media such as electronic media and conventional media. Technology is included in electronic media (e-media). Mclanahan et. al. (2008) in their book entitled "Children and Electronic Media" state that media technology is an integral part of children's lives in the 
twenty-first century. From their result of research, it is important to get students attention through electronic media (e-media).

Visual learning can be easier to understand and deal with their learning (Baharul et.al. 2014). Visual images of animation video can help to convey meaning (Devi, 2014). She also stated that visual images of animation can help the students to understand and tell the meaning of the visual images of animation. The students get the meaning easily because of the animation. In a video there are some actions which help the learner to construct their understanding of the message of the expression that is shown. The learner easily get the meaning of the language used by shown picture and heard the right pronunciations with good tone.

From the explanation about the importance of e-media in teaching and learning process, this study would design and develop suitable culture based English e-media to promote character education of curriculum 2013. The e-media is integrated with Balinese local culture.

\section{Methods}

This study was conducted in junior high schools in Buleleng Sub district. There were 9 junior high schools. Those schools were SMP Negeri 1 Singaraja, SMP Negeri 2 Singaraja, SMP Negeri 3 Singaraja, SMP Negeri 4 Singaraja, SMP Negeri 5 Singaraja, SMP Negeri 6 Singaraja, SMP Negeri 7 Singaraja, SMP Laboratorium UNDIKSHA, and SMP Mutiara Singaraja.

The subjects of this study were the English teachers and the first semester of seventh grade students in Buleleng Sub district. The object of this study was English learning media for the first semester of seventh grade students of junior high school which were based on local culture in order to support the development of the character education.

This research was classified as a research and development research in which could be defined as research method used to establish a certain product and test the quality of its effectiveness. Research and development research is the systematic study of design, development and evaluation process with the goal to establish an empirical basis for the creation of instructional and non-instructional products (Sugiyono, 2013). This research was developed by using the design based on a model proposed by Peffers et al. (2007). This design consist of six phase.

\section{Identify the problem}

Define the specific research problem and determine the value of a solution (Peffers, 2007). Because the problem definition was used to develop an artifact that can provide a solution, it may be beneficial to atomize the problem conceptually so that the solution can capture its complexity. Identifying the problem was conducted by collecting document and interview. Based on the interview from teachers of grade VII of junior high school in Buleleng, media was very important to support the teaching and learning process. Since this was for young learner, e-media was better. E-media contains visual animation that can attract students' attention. But the problem was the school did not provide tools to support the implementation of e-media. The teachers' knowledge about implementing e-media was also limited. They also believed that integrating culture in the media was beneficial for the students. It could be the form of culture heritage to build better character on the students because culture contains many good moral values. One way to integrate culture in the teaching and learning process is by using e-media. That is why it is needed to develop a culture-based e-media for the second semester of grade VII of junior high school in Buleleng. 


\section{Describe the objectives}

Describe the objective was conducted after identifying the problem. The objective of this research is to develop culture-based English e-media to support the implementation of curriculum 2013 for the second semester of grade VII of junior high school in Buleleng.

\section{Design and develop the artifact}

Create the artifact based on the objectives. The artifact of this study was culture-based English e-media for the second semester of grade VII of junior high school in Buleleng. The e-media was developed by using adobe flash program. The design and development of the artifact was based on the need analysis. In designing phase, need analysis is used to get the information of what kind of media is expected to support the implementation of curriculum 2013 and character building. The analysis of learning sources is also conducted in order to know the appropriate and the relevance of the design and development of culture-based English e-media to support the implementation of curriculum 2013 for the second semester of grade VII of juior high school in Buleleng.

\section{Test the artifact}

After design and develop the artifact, the researcher tested the e-media through expert judgement. The e-media was tested by experts in order to get their opinion, assessment, correction, advice and input regarding to the content and the quality of the e-media.

\section{Evaluate the testing result}

Evaluation was conducted after testing the artifact. Evaluating the e-media by the experts was to improve the quality of the e-media.

\section{Communicate the testing result}

The last step was communicate the testing result in the form of written and presentation. The communication was conducted at the time the research was defended in front of judges.

There were several instruments in collecting the data for this research such as document, field note, and expert judgment form. There were several steps in procedure of data collection in this study for need analysis and the validation of the product from expert of ELT, ICT and the expert on social and culture studies.

\section{Creating the product}

After conducting FGD with the teachers in 11 junior high schools in Buleleng Sub district, data was analyzed by researcher. In creating the product, researcher used the result of need analysis as the guideline. The result of need analysis helped researcher to create appropriate product.

\section{Validating the product of the research by experts of learning media.}

Developed culture-based learning media was validated by expert on English Language Teaching, expert on multimedia design, and expert on socio-cultural studies in order to make the product more reliable and valid. The researcher evaluated the product by using field note as the instrument. The evaluation were processed in qualitative analysis.

\section{Findings}

\section{Findings and Discussions}

The purpose of this study was to support the development of Balinese local culture based e-media of English language instruction to support the implementation of Curriculum 2013 for the first semester grade VII of junior high school in Buleleng Sub district. The finding of this research will be discussed below.

\section{Identifying the problem}

The researcher identified the problem of English learning media that existed in junior high school especially in Buleleng sub-district. In identifying the problem, English teachers in 9 junior high schools in Buleleng sub-district had been interviewed though the distribution 
of teachers questionnaire and students' questionnaire, and got relevancy validation from the socio cultural experts. Those were used by the researcher to design and develop the product.

\section{Designing and Developing the Product}

\section{Syllabus Analysis}

The researcher needed to know the basic requirement that should be achieved by the junior high school students. The government has design and publishes the Syllabus of Curriculum 2013 for the Junior High School in Indonesia. The researcher used syllabus as the instrument to design and develop the product. Syllabus was the basic requirement of teaching and learning process. So, syllabus of curriculum 2013 takes a role as the basic requirements to lead the teacher design lesson plan, create appropriate learning media, and time allotment or duration in learning. Those were conducted in order to produce appropriate electronic media which meet the character education that was involved in the Syllabus of Curriculum 2013.

Based on the syllabus curriculum 2013 and relevancy validation by the socio cultural experts, the researcher designed content of the product. All of components in syllabus, character education, and local culture aspect were combined in a form of blue print. Based on the blue print the researcher could design the media which consisted of listening, speaking, reading, writing skills, and vocabulary that the students needed to learn.

The researcher analyzed basic competencies, character educations, and local cultures into 4 themes. The researcher analyzed which basic competencies and character education were match and followed by the local culture aspect based on those character educations. Character education and local culture used were based on the relevancy validation which was validated by the socio cultural expert. There were 4 themes that were designed, such as: Balinese Wedding Ceremony, Ngayah, Melasti, and Balinese Carving. The researcher constructed the content of the product in a form of blue prints in order to help the researcher developed the product.

Beside the basic requirements of the syllabus that should be included, the researcher also designed the product based on the criteria of good media. Aspects of good media such as educational, technical, and aesthetic were included. The construction of the media was based on educational aspect such as educational curriculum and syllabus of Curriculum 2013. The product also helped in increasing students' motivation, the media also pushed students' activity and creativity, and also based on the stage of students' development.

The term of physical aspect could be seen from the purpose and function of e-media. There were 11 criterion which take a role in developing media. The media designed had been developed in accordance with the purpose and function of media, the media designed had been developed to be able to develop all aspects of children development (emotional, cognitive, and psychosocial), the material of the media designed had been gotten easily in surrounding. The media were also safe for the children. This media were easy to use by students and teachers, the media designed had helped to improve students' interest and motivation.

From the aesthetic aspect, the media designed had met all three criteria of good media. The media had been developed in an appropriate size to be used as media. The media were attractive form, and had been developed with combination of colour which were matching and attempting.

After constructed blue print of the product, the researcher collected resources, references, and texts. The researcher also made conversations and any features which related with the product. Based on the blue print as plan and draft of the product the researcher began to develop the product. Here the following procedures of making the product. 


\section{Developing the lay out}

The design of the e-media was developed based on the blue print made by the researcher. It was designed by using adobe photo shop, freemake video converter, and Adobe Flash CS6. All those software had different function in the development of e-media. From the blue print, the researcher began to design the layout based on the topic selected. The background design, character and button were made first. After the layout was constructed, the researcher prepared the material that would be inserted in the e-media.

\section{Developing the materials}

The researcher collected the materials used in the e-media from English book of grade VII of junior high school and from the internet. Some of the videos were made by the researcher in the form of custom animation.

The details of the development of the material are described bellow.

1. Working with images.

The images were created by using Adobe Photoshop and some were downloaded from the internet. The image was created based on the Balinese local culture. All the buttons were made by using Adobe photo shop program.

2. Working with audios.

The audios in the e-media was used as conversation, material pronunciation, music, and sound effect. Hand phone was used to record the audios for those function. The recording was in the form of Mp3. The music background was taken from the internet.

3. Working with videos and animation.

The custom animation videos were made by mixing several images and audios. The images and audios were combined by using Adobe Flash CS6 program. The character in the animation was made by using Adobe Photoshop.

The researcher analysed the result of expert judgement form by using SPSS 16.0 version. The score given by the experts were analysed in order to find out the reliability of the culture-based English e-media. The researcher analysed the scores of each item of the criteria by inputting those scores to the SPSS 16.0 program and used the reliability analysis Cronbach's Alpha Coefficient to measure the reliability of the result of expert judgement data. The result of the data was analysed by using SPSS 16.0 program.

The measurement instrument can be judged reliable if the Cronbach Alpha is or above 0.70 . The reliability of the data in this study was 0.735 . It can be concluded that the data has high consistency or is reliable. After finding out the reliability of the data, the researcher would compute the mean score of each aspect and total mean score for all aspects. The researcher used Microsoft Excel 2013 to analyse the mean score of each aspect.

As the result of the analysis of mean score from both of the experts, the total score was 3.8. According to the score categories which had been formulated in the research design in this study, the final score could be categorized as good. From the mean score, it could be concluded that the quality of the product of culture-based English e-media for grade VII of junior high school students was good. It has been convinced by the experts.

The mean score of each criterion showed different result. From first aspect of the criteria overall impression about the media, this e-media was categorized as having good quality with total mean score of 4.0. It meant that the e-media was appealing and inviting enough to be used in presenting English lesson for grade VII of junior high school students in Buleleng.

For the audience and purpose aspect, this culture-based e-media showed the mean score of 4.3. It can be categorized as excellent quality. The culture based English e-media is convinced by both experts could meet the needs of specific audience in this study. Moreover, 
the experts believed that the culture based English e-media has addresed the Balinese local culture and the materials are appropriate for the first semester of grade VII of junior high school students because the e-media covers core competency and basic competency of the syllabus. So the studentscould achieve the learning objectives.

Futhermore, the mean score in the content aspect, this e-media obtained 3.8 as the mean score which means that the culture-based English e-media has a good quality of content in terms of authentic resources, relevant materials that integrated with Balinese local culture. the materials are designed based on basic competency and indicator and also additional exercises.

In term of language, the culture-based English e-media has good quality. The mean score is 3.5. Eventhough the e-media is categorized having a good quality of language, there were some grammatical and spelling errors. Those errors has been revised by the researcher.

From the aspect of organization, the mean score of this e-media is 3.75. the e-media can be classified as a good e-media which has a clear introduction, organized elements and presented in logical sequence. It would ease the students and also teachers in using this emedia.

The design of the culture-based English e-media can be categorized as good quality. The mean score in terms of design is 3.9. The e-media has good visual appealing that could attract the students' attention. The e-media was provided by the experts having creative and imaginative design that can be seen from the background colors, interesting pictures, and also visible fonts. The e-media also effective to facilitate the students in learning by giving the information and exercises.

For the navigation aspect, the culture-based English e-media has mean score 3.8. It means that the direction and help are effectively useable. Although it can be categorized having a good navigation, it still need to be revised in some parts of button to improve the effectiveness of the e-media. The technical overall aspect in the e-media has the mean score 3.6 which means that the e-media have already showed smoothness to run this e-media from start to finish.

From the aspect of technical animation, the e-media obtained mean score 4.0. It means that the e-media having a good quality in terms of animation. the animation could make the students interested in learning rather than distract their attention. The last aspect in the criteria is technical interaction. This criteria obtain mean score 3.2. It means that the culture-based English e-media having sufficient quality in terms of interaction and feedback. The e-media had poor feedback and it had been revised by the researcher.

Based on the description of data analysis, this culture based English e-media can be categorized as a good e-media for the first semester of grade VII of junior high school in Buleleng. The product of culture-based English e-media developed by the researcher has met the objective of this study to design and develop a culture-based English e-media for the first semester of grade VII of junior high school in Buleleng. The e-media could give contribution in supporting the implementation of curriculum 2013 of the first semester of grade VII of junior high school in Buleleng.

The culture-based English e-media is ready to be used by the teacher of the junior high shcools in Buleleng as the effective instruction tool to facilitate the students in learning the language as well as Balinese local culture. This e-media also could facilitate students in learning English in innovative way. As conclusion, culture-based English e-media for the first semester of grade VII of junior high school in Buleleng is a good e-media to support the implementation of curriculum 2013. 


\section{Discussions}

The culture-based English e-media was developed by the researcher to support the implementation of curriculum 2013 for the first semester of grade VII of junior high schools in Buleleng. The culture-based English e-media could facilitate students in learning English as well as Balinese local culture. It is needed by the teacher and students in order to support the implementation of curriculum 2013 which is emphasizing on character education. Mclanahan et. al. (2008) said that inserting local culture to the materials also promote character building because the moral value in the local culture can build better character on the students.

The development of culture-based English e-media in this study was focused on seventh grade students in the first semester of junior high schools in Buleleng. The researcher designed and developed the culture-based English e-media based on need analisys. The need analisys was conducted in order to know what kind of media is expected to be developed to support the implementation of curriculum 2013 which is emphasizing on character education. Since the e-media was used to support character education, the researcher choose the appropriate local culture to be integrated on the e-media.

Based on the English book of the grade VII for junior high schools curriculum 2013, there are five chapters. In the e-media, there are four main topic. There in one topic that consist of two chapters. The four main topics are Wedding Ceremony, Melasti, Ngayah, and Balinese Carving. The culture-based English e-media provided some exercise to help students achieve all indicators in each basic competency. The researcher also provided some pictures that is related to the topic and materials as the introduction. Each topic has main menu that consist of skills, materials, vocabulary and let's sing a song (video).

In the skills menu, there are four sub menu. They are listening, reading, speaking, and writing. In the listening activity, there is a video animation of two people talking to each other. The students would listen to the audio of language expression that is related to the topic. The audio is in the form of short dialogue. In the speaking section, the e-media provide conversation that is related to the topic. The students were asked to perform the dialogue with their friend after the teacher give example. It is good for the students to have model first before they have such activities. There are also pronunciation practices in the speaking section in order to make the students know the correct pronunciation of certain words. The students only need to click the words and they could listen the correct pronunciation. In the reading section, students are provided some text that is related to the topic. In the writing section, students are provided some exercise that required the students to write something. There are also some pictures that is related to the material to help the students in constructing what they are going to write.

The e-media also provide the materials to be learnt further by the students. The materials consist of some language expression that is related to the topic. Some interesting pictures also provided to help the students in understanding materials. The pictures also could make the students more attracted in learning. The materials also provide some question to be answered. The students could check whether their answer is correct or not. The culture-based English e-media provided vocabulary spot that could help the students know the meaning of certain Balinese terms that related to the topic such as: penjor, pelinggih, ogoh-ogoh, etc. Video also provided in the e-media as an entertainment also related to the materials. The video contains songs and language expression that is used in the materials. Therefore, the menu in the e-media was developed for specific purposes which was designed to help the teaching and learning process and build better character on the students.

This e-media had been judged by two experts. One is lecturer in English education department, and the other expert was a teacher in SMP Negeri 1 Singaraja. The two experts were I Putu Ngurah Wage Myartawan, S.Pd., M.Pd. and Drs. Andang Kinaryo Adji, S.Pd. 
Both of them have expertise in terms of English and e-media. The experts assessed the culture-based English e-media in the form of summative assessment. The result of the expert' judgement were varied. According to the reliability analysis in the table 4.4 showed that this culture based e-media has highly consistency or can be categorized as reliable. It is showed from the Cronbach's Alpha Coeficient that the reliability of the data was 0.735 . The measurement instrument can be judged reliable if the Cronbach Alpha is or above 0.70. Futhermore, the result of the total mean score ao all the aspects of the criteria in this study is 3.8. According to classification of mean score in this study, culture-based English e-media can be categorized as a good quality e-media.

According to the analisys, the two experts pointed out there were one aspects categorized as sufficient. It is the technical interaction aspect. Both of the experts said that it is needed to add some exercise and feedback for the students to check their understanding. This aspect had been revised by the researcher to make improvement in term of the quality of the e-media. based on those data analisys, it can be summarized that the culture-based English e-media is appropriate for the first semester of Garde VII students of junior high school in Buleleng.

There sre some theories about the fucntion of the media that supported the result of the data analisys conducted by the researcher. Levie \& Lentz in Arsyad (2011) propose four function of leraning media, especially visual media such as: attention function, affective fucntion, cognitive function, and compensatory function. The culture based English e-media have already fullfiled those criteria. Moreover, according to (Rias, 2011), Animation in multimedia is said to be beneficial to learning especially when the learning material demands visual movements. This Culture-based English e-media have already contain some custom animation that is believed beneficial in teaching and learning process. This e-media could be used by the students and teachers in the classroom and some of the activities can be done outside the classroom as computer assisted learning. By using this e-media, teachers could save the time because thay do not need to explain about the materials too much. Moreover, this e-media was developed based on the students' need in seventh grade of the first semester of junior high schools in Buleleng. The culture-based English e-media also fulfilled the instrcutional appropriateness in which it could facilitate students in learning English as well as Balinese local culture.

The culture-based English e-media was developed in order to support the implementation of curriculum 2013 which is emphasized on character education. The culture was integrated in the e-media to build a better character on the students. Devi (2014) also conducted research on inserting local culture in English language teaching to promote character education. She stated that by integrating local cultural values in the practices of English language teaching to promote character education, it is commonly believed plays important roles in encouraging, improving, and maintaining the spirit of nationalism of the next generation. So, the culture-based English e-media is very beneficial to support character education, cultural heritage and English learning activities.

\section{Conclusion}

The culture-based English e-media was developed by using the Peffers et al. research and development design. There were six steps which is needed to be conducted by the researcher, they are: (1) identify the problem motivating the research, (2) describe the objectives, (3) design and develop the product, (4) subject the product to testing, (5) evaluate the result of testing, and (6) communicate those results in the form of thesis report. The quality of culture-based English e-media for the first semester of grade VII of junior high school in Buleleng was categorized as a good e-media. It is according to data analysis by using Cronbach's Alpha Coefficient which showed significant reliability result 0.737 . This e- 
media was categorized reliable because the result of reliability analysis was above 0.70 . Futhermore, it is proved the result of mean score analysis using Microsoft excel 2013 which showed that the total mean score of all the aspect of the criteria in this study was 3.8. Based on the classification of mean score in the research design in this study, culture-based English e-media can be categorized as having a good quality of e-media for the first semester of grade VII of junior high schools.

There are some suggestion to the further researcher who wants to conduct similar research:

1. Further research need to be conducted in order to investigate the effectiveness and the implementation of this culture-based English e-media towards the development of students' ability in English especially for the seventh grade of junior high school in Buleleng.

2. This research focused on developing culture-based English e-media to facilitate the teachers and students in the classroom or outside classroom. Even though this media could facilitate the students in learning, this e-media still lack in providing independency for students because it is not purely IMM (Interactive Multimedia) that could provide independent learning for students. For further research, it is better to develop e-media but give emphasize on developing the IMM to facilitate students with independent learning effectively.

The product evaluation is also important. There were some problems during the revision of the e-media. The product have been revised based on the experts' suggestion. The revision needs a long time. Therefore, it is suggested for the further researcher to conduct the expert judgement as early as possible.

\section{References}

Arsyad, Azhar. 2011. Media Pembelajaran. Jakarta. PT. Raja Grafindo Persada.

Baharul Islam Md et. al. 2014. Child Education Through Animation: An Experimental Study. International Journal of Computer Graphics \& Animation (IJCGA), 4 (4)

Devi, Ika (2014). Animation Video to Improve Students' Vocabulary Mastery. Retrieved on March $17^{\text {th }} 2014$.

McLanahan et. al. 2008. The Future of Children. Children and Electronic Media PrincetonBrookings, 18 (1).

Peffers et al. 2007. A Design Science Research Methodology for Information Systems Research. Journal of Management Information Systems, 24 (3).

Rias et al. 2011. The Effects of Varied Animation in Multimedia Learning: Is the extra effort worthy? International Journal of Digital Information and Wireless Communications (IJDIWC), 1 (3).

Sugiyono, 2013. Metode Penelitian Pendidikan: Pendekatan Kuantitatif, Kualitatif, dan $R \& D$. Bandung, Penerbit Alfabeta. 